\title{
AERODYNAMIC IMPROVEMENT OF CENTRIFUGAL COMPRESSOR STAGE IMPELLERS
}

\author{
Institute of Technical Mechanics \\ of the National Academy of Sciences of Ukraine and the State Space Agency of Ukraine, \\ 15 Leshko-Popel St., Dnipro 49005, Ukraine; e-mail: yukv@i.ua; zinevich7385@gmail.com
}

This work is devoted to the development of approaches to the optimal aerodynamic design of centrifugal compressor stages, which is topical because of their use in compressors of modern aircraft gas turbine engines and power plants. The aim of this work is to construct a technique for aerodynamic improvement of centrifugal compressor stage impellers and to verify its effectiveness. The basic method is a numerical simulation of 3D turbulent gas flows in impellers on the basis of the complete averaged Navier-Stokes equations and a two-parameter turbulence model. The approach to optimization employed in this work features: varying the 3D shape of an impeller blade at a fixed position of its entrance and exit portions to minimize the effect of the shape variation on the operating range of the impeller airflow rate and the flow parameters at the impeller exit, formulating quality criteria as airflow-averaged impeller power characteristics, and searching for advisable values of the impeller blade geometric parameters by systematically scanning the independent-variable region at points that form a uniformly distributed sequence. The numerical investigation conducted showed that the proposed technique offers a sizeable increase in the compression ratio of a centrifugal impeller while keeping its adiabatic efficiency within the operating range of the impeller airflow rate. This conclusion was made when using rather a "coarse" computational grid, which, however, retains the sensitivity of the computed results to a variation in the centrifugal impeller blade shape. This conclusion was verified by a subsequent calculation of the power characteristics of the original and the modified impeller on a finer grid. On the whole, it was shown that varying the shape of the middle part of a centrifugal impeller blade alone has a pronounced effect on the impeller compression ratio, while leaving the impeller adiabatic efficiency almost unaffected. The results obtained may be used in the aerodynamic optimization of centrifugal stages of aircraft gas turbine engines.

Keywords aerodynamic improvement, impeller, 3D blade shape, centrifugal compressor stage, numerical simulation, power characteristics.

1. Benini E., Giacometti S. Design, manufacturing and operation of a small turbojet-engine for research purposes. Applied Energy. 2007. V. 84. Pp. 1102-1116.

2. Rekstin A. F., Galerkin Yu. B. Features of the primary design of low-flow centrifugal compressor stages (in Russian). Vestnik Prmskogo Natsionalnogo Issledovatelskogo Universiteta. Mashinostroyeniye, Materialovedeniye. 2018. V. 20. No. 2. Pp.. 43-54.

3. Poursadegh F., Hajilouy A., Nili M. A novel quasi-3d design method for centrifugal compressor impeller on the blade-to-blade plane. Proc. of ASME TURBO EXPO 2011. (Vancouver, June 6-10, 2011). Vancouver, British Columbia (Canada), 2011. 8 pp.

4. Xiaomin Liu, Wenbin Zhang. Two schemes of multi-objective aerodynamic optimization for centrifugal impeller using response surface model and genetic algorithm. Proc. of ASME TURBO EXPO 2010. (Glasgow, June 14-18, 2010). Glasgow (UK), 2010. 13 pp.

5. Jin-Hyuk Kim, Jae-Ho Choi, Kwang-Yong Kim. Design optimization of a centrifugal compressor impeller using radial basis neural network method. Proc. of ASME TURBO EXPO 2009. (June 8-12, 2009). Orlando, Florida (USA), 2009. 9 pp.

6. Vasil'ev Yu. S., Galerkin Yu. B., Soldatova K. V. Turbomachine flow passage optimization (by the example of centrifugal compressors) (in Russian). Problemy Energetiki. 2011. No. 9-10. Pp. 105-117.

7. Noll B. Evaluation of a Bounded High-Resolution Scheme for Combustor Flow Computations. AIAA J. 1992. V. 30. No. 1. Pp. 64-69.

8. Rublevsky .Yu., Plakushchy D. A., Pis'menny V. I., Kvasha Yu. A. Numerical study of a two-stage fan (in Russian). Vestnik Dvigatelestroyeniya. 2013. No. 2. Pp. 169-176.

9. Pis'menny V. I., Kvasha Yu. A. Calculation of a 3D air flow in a centrifugal compressor stage (in Russian). Teh. Meh. 2004. No. 2. Pp. 94-99.

10. Sobol I. M., Statnikov R. B. Choice of Optimum Parameters in Multicriteria Problems (in Russian). Moscow: Nauka, 1981. 110 pp.

11. Kvasa Yu. A., Zinevych N. A. On the choice of computational grids in numerical simulation of 3D turbulent flows in supersonic compressor stage impellers (in Russian). Teh. Meh. 2013. No. 3. Pp. $34-41$.

12. Kvasa Yu. A., Zinevych N. A. On objective function interpolation in the optimization of engineering systems (in Russian). Teh. Meh. 2018. No. 2. - Pp. 71-78. 